\title{
Investigating the Factors That Determine Tertiary Students Brand Choice of Mobile Phones in Northern Ghana
}

\author{
Michael Dergol-Dery ${ }^{1}$, Alexander Suuk Laar ${ }^{2, ~}{ }^{*}$, Mohammed Abdul-Gafaru ${ }^{3}$, Naazuing Valeria ${ }^{4}$ \\ ${ }^{1}$ Chiraa S. H. S. Mathematics Department, Chiraa-Sunyani, Ghana \\ ${ }^{2} \mathrm{C} / \mathrm{O}$ Ghana Health Service/ PATH-Ghana, Maternal and Child Health Unit, Accra, Ghana \\ ${ }^{3}$ TAMALE, S. H. S Mathematic Department, Tamale, Ghana \\ ${ }^{4}$ C/O Tebri Francis Xavier T. I. Ahmadiyya S. H. S., Mathematics Department, Kumasi, Ghana \\ Email address: \\ dego18181@gmail.com (M. Dergol-Dery), laar.alex.suuk@gmail.com (A. S. Laar), mohammedabdulgafaru@gmail.com (M. Abdul-Gafaru), \\ naazuingvaleria232@gmail.com (N. Valeria) \\ ${ }^{*}$ Corresponding author
}

\section{To cite this article:}

Michael Dergol-Dery, Alexander Suuk Laar, Mohammed Abdul-Gafaru, Naazuing Valeria. Investigating the Factors That Determine Tertiary Students Brand Choice of Mobile Phones in Northern Ghana. International Journal of Information and Communication Sciences.

Vol. 2, No. 2, 2017, pp. 24-29. doi: 10.11648/j.ijics.20170202.12

Received: March 16, 2017; Accepted: April 15, 2017; Published: June 8, 2017

\begin{abstract}
This paper investigated the factors affecting students brand choice for mobile phones among university students at the University for Development Studies, Navrongo Campus in the Upper East region of Ghana. The research was a crosssectional design with 300 students. The students were chosen using stratified random sampling. Statistical Package for Social Sciences version 20 was used to analyze the data. The results show that three major factors directly influencing students choice of brand of mobile phones in this study were user-friendliness, quality and price. Among all the mobile phone brands, the most used brands by the students were Nokia and Samsung. Nokia and Samsung together constituted 56 percent of phones used by the respondents. However, for future use, 45 percent are planning to use Nokia while 61 percent for Samsung. The price of mobile phones ranged between GHC 50.00 and GHC 301.00. Fashion and durability were factors that correlated and have relationships with the decision to buy a brand of mobile phone. This is one of the few studies in consumer behavior to assess preferences in a consumption context of mobile phone industry. The findings are useful for mobile phone dealers and manufacturers to incorporate these preferences by diversifying the types of mobile phones with different ranges of corresponding prices to meet consumers' needs and income levels.
\end{abstract}

Keywords: Mobile Phone, Brand, Affordability, Students, Ghana

\section{Introduction}

Mobile phones are one of the modern telecommunication technologies that have emerged over the past decades to facilitate communication among people within and across countries. Today, it has become a key communication tool and an essential part of everyday lives [1] and in both private and public institutions in Ghana. To increase telephone coverage, Ghana liberalized its telecommunication sector in the early 1990s to provide consumers with better, new and less costly telecom services [2]. This was done through the introduction of a five-year Accelerated Development Programme in 1994, to allow private participation in all sectors of the telecom industry [3].
Mobile phones are not only used for making calls, but among other functions, for text-messages as well as for internet browsing. The growing demand for mobile telephony services in Ghana has resulted in the creation of a wide mobile phone handset market. Marketing of mobile handsets has therefore taken a pulsating expansion, with new sophisticated handsets being introduced onto the market every now and then. It has also become fashionable to own a mobile phone. In recent times, apart from the acquisition of the phone and the type of phone one possesses is now the issue.

The need for fashionable phones has also caught up with 
the mobile phone manufactures as they also manufacture new and fashionable mobile phones within short intervals of time to meet the taste of consumers. In a way, there seems to be a competition among the mobile phone manufacturers as they must provide latest and fashionable mobile phones to satisfy their customers. In Ghana mobile phone usage has become common, but there are numerous factors that need to be taken into account when choosing a brand of mobile phone. Consumer research in Ghana has devoted little specific attention to factors that determine choice of brand of mobile phones. It is against this background that this study was undertaken to examine the factors that determine students brand choice of mobile phones in a tertiary institution.

\section{Method}

\subsection{Study Context}

The University for Development Studies (UDS) was established in May 1992 by PNDC Law 279 to blend the academic world with that of the community in order to provide constructive and meaningful interaction between the two for the total Development of Northern Ghana, in particular, and Ghana as whole. It began academic work in September 1993 with the first batch of thirty-nine (39) students admitted into the Faculty of Agriculture, Nyankpala in Tamale

The University's principal objective is to address and find solutions to the environmental problems and socio-economic deprivations that have characterized northern Ghana in particular and are also found in some rural areas throughout the rest of the country including the Faculty of Applied Sciences, Faculty of Mathematical Sciences Navrongo Campus this study area.

\subsection{Research Design}

The research was a cross-sectional design with 300 students. The researchers employed face to face administration of questionnaires to collect the data. English language was employed as the medium of communication with the students.

\subsection{Sampling Technique}

The students were obtained using stratified random sampling. A random sample from each stratum was taken in proportional to the stratum's size when compared to the population. These subsets of the strata were then pooled to form a random sample. The researchers employed this technique because the study population is mainly students in Navrongo campus which are in levels.

\subsection{Data Analysis}

The statistical Package for Social Sciences version 20 was used to analyze the data and presented in the form of frequency tables and histograms. Data was further analyzed using regression, chi-square and factor analysis.

\section{Results}

For the 300 respondents surveyed, 182 (60.7\%) were males and118 (39.3\%) were females in Table 1.

Table 1. Gender of respondent.

\begin{tabular}{llllll}
\hline & Frequency & Percent & $\begin{array}{l}\text { Valid } \\
\text { Percent }\end{array}$ & $\begin{array}{l}\text { Cumulative } \\
\text { Percent }\end{array}$ \\
\hline \multirow{3}{*}{ Valid } & Male & 182 & 60.7 & 60.7 & 60.7 \\
& Female & 118 & 39.3 & 39.3 & 100.0 \\
& Total & 300 & 100.0 & 100.0 & \\
\hline
\end{tabular}

\subsection{Prices of Mobile Phones}

The prices of mobile phones ranged from GHC 50 and below to GHC 301 and above. The greater number of the respondents owned phones that ranged fromGHC151-200. For cost of a phone below GHC50 and above GHC301, 8\% of each was owned by the respondents' details in figure 1 .

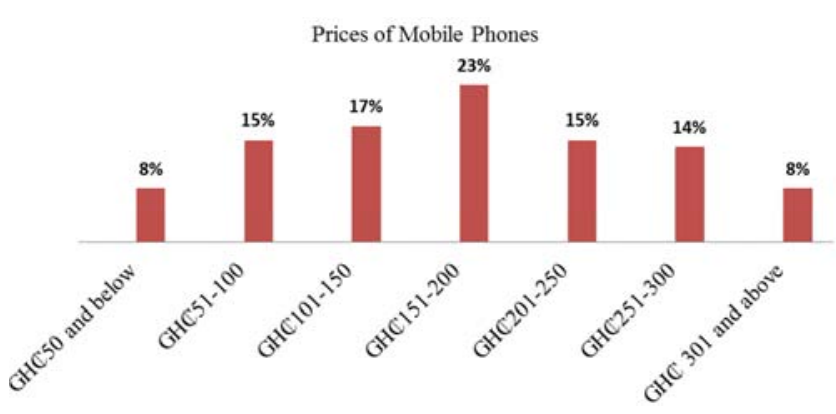

Figure 1. Prices of Mobile Phones.

\subsection{Brands of Mobile Phone Used and Preference}

Among all the mobile phone brands, the most used brand among the respondents was Nokia31\% followed by Samsung $25 \%$. Samsung was the most preferred brand $61 \%$ followed by Nokia $45 \%$. The least used mobile phone brand was Motorola accounting for $3 \%$ of the students' phone ownership in the University Details in figure 2.

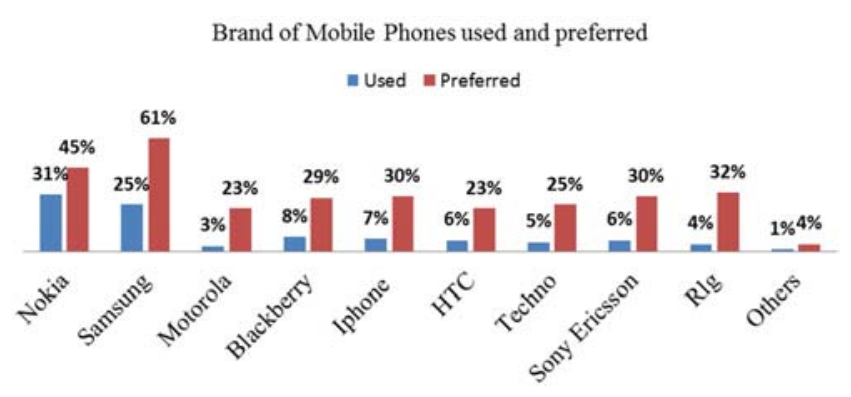

Figure 2. Brands of mobile phone used and preferred.

\subsection{Relationship Between Mobile Phone Brand and Gender}

The results showed that there was a relationship between mobile phone brand and gender $(\mathrm{P}=0.000)$. Thus, a person use of a brand of mobile phone depends on his/her gender. Details in table 2. 
Table 2. Cross-tabulation of mobile phone brand against gender.

\begin{tabular}{|c|c|c|c|c|c|}
\hline & & & \multicolumn{2}{|c|}{ Gender of respondent } & \multirow{2}{*}{ Total } \\
\hline & & & Male & Female & \\
\hline \multirow{20}{*}{ Brand of mobile phone } & \multirow{2}{*}{ Nokia } & Count & 68 & 27 & 95 \\
\hline & & Expected Count & 57.6 & 37.4 & 95.0 \\
\hline & \multirow{2}{*}{ Samsung } & Count & 28 & 46 & 74 \\
\hline & & Expected Count & 44.9 & 29.1 & 74.0 \\
\hline & \multirow{2}{*}{ Motorola } & Count & 6 & 4 & 10 \\
\hline & & Expected Count & 6.1 & 3.9 & 10.0 \\
\hline & \multirow{2}{*}{ Blackberry } & Count & 17 & 7 & 24 \\
\hline & & Expected Count & 14.6 & 9.4 & 24.0 \\
\hline & \multirow{2}{*}{ Iphone } & Count & 15 & 7 & 22 \\
\hline & & Expected Count & 13.3 & 8.7 & 22.0 \\
\hline & \multirow{2}{*}{ HTC } & Count & 9 & 8 & 17 \\
\hline & & Expected Count & 10.3 & 6.7 & 17.0 \\
\hline & \multirow{2}{*}{ Techno } & Count & 12 & 3 & 15 \\
\hline & & Expected Count & 9.1 & 5.9 & 15.0 \\
\hline & \multirow{2}{*}{ Sony Ericsson } & Count & 8 & 11 & 19 \\
\hline & & Expected Count & 11.5 & 7.5 & 19.0 \\
\hline & \multirow{2}{*}{ Rlg } & Count & 10 & 3 & 13 \\
\hline & & Expected Count & 7.9 & 5.1 & 13.0 \\
\hline & \multirow{2}{*}{ Others } & Count & 9 & 2 & 11 \\
\hline & & Expected Count & 6.7 & 4.3 & 11.0 \\
\hline \multirow{2}{*}{ Total } & & Count & 182 & 118 & 300 \\
\hline & & Expected Count & 182.0 & 118.0 & 300.0 \\
\hline
\end{tabular}

$=31.485 \mathrm{df}=9 \mathrm{p}$-value $=0.000$.

There existed no association between price and age of students $(\mathrm{P}=0.400)$. Thus, either a student is above the age of 30 years or between 18 to 21 years had nothing to do with the affordability of a brand of a mobile phone in Table 3 .

Table 3. Cross-tabulation of price of phone against Age of respondent.

\begin{tabular}{|c|c|c|c|c|c|c|c|}
\hline & & & \multicolumn{4}{|c|}{ Age of respondent } & \multirow{2}{*}{ - Total } \\
\hline & & & 18-21 & $22-25$ & 26-29 & 30 and above & \\
\hline \multirow{14}{*}{$\begin{array}{l}\text { Price } \\
\text { GHC }\end{array}$} & \multirow{2}{*}{50 and below } & Count & 7 & 4 & 11 & 4 & 26 \\
\hline & & Expected Count & 5.2 & 7.7 & 8.0 & 5.1 & 26.0 \\
\hline & \multirow{2}{*}{$51-100$} & Count & 7 & 11 & 17 & 10 & 45 \\
\hline & & Expected Count & 9.0 & 13.4 & 13.8 & 8.8 & 45.0 \\
\hline & \multirow{2}{*}{$101-150$} & Count & 12 & 14 & 15 & 10 & 51 \\
\hline & & Expected Count & 10.2 & 15.1 & 15.6 & 10.0 & 51.0 \\
\hline & \multirow{2}{*}{$151-200$} & Count & 12 & 22 & 23 & 13 & 70 \\
\hline & & Expected Count & 14.0 & 20.8 & 21.5 & 13.8 & 70.0 \\
\hline & \multirow{2}{*}{$201-250$} & Count & 6 & 14 & 14 & 10 & 44 \\
\hline & & Expected Count & 8.8 & 13.1 & 13.5 & 8.7 & 44.0 \\
\hline & \multirow{2}{*}{$251-300$} & Count & 10 & 19 & 4 & 8 & 41 \\
\hline & & Expected Count & 8.2 & 12.2 & 12.6 & 8.1 & 41.0 \\
\hline & \multirow{2}{*}{300 and above } & Count & 6 & 5 & 8 & 4 & 23 \\
\hline & & Expected Count & 4.6 & 6.8 & 7.1 & 4.5 & 23.0 \\
\hline \multirow{2}{*}{ Total } & & Count & 60 & 89 & 92 & 59 & 300 \\
\hline & & Expected Count & 60.0 & 89.0 & 92.0 & 59.0 & 300.0 \\
\hline
\end{tabular}

Chi-square $=18.864 \mathrm{DF}=18 \mathrm{P}$ - value $=0.400$.

\subsection{Factors That Influence the Choice of Brand of Mobile Phone}

We performed factor analysis to determine factors that influence choice of brand of mobile phones. The analysis consisted of six variables: Age, Price, More Features, Fashionable, Portability and durability. A correlation coefficient of 0.7 or greater was considered as being high. There is high correlation between the variables such as fashionable and more features (0.887) shown in table 4 . Thus, a mobile phone tends to be fashionable, if only it has more features. 
Table 4. Correlation Matrix ${ }^{a}$

\begin{tabular}{lllllll}
\hline & Age & Price & More features & Fashionable & Portability & Durability \\
\hline Age & 1.000 & -.433 & .439 & .498 & .011 & -.002 \\
Price & -.433 & 1.000 & -.027 & -.033 & -.083 \\
More features & .439 & -.027 & 1.000 & .877 & -.085 \\
Fashionable & .498 & -.033 & .877 & 1.000 & -.156 \\
Portability & .011 & -.002 & -.085 & -.156 & 1.000 &. .169 \\
Durability & .763 & .083 & -.121 & -.169 & .397 & 1.000 \\
\hline
\end{tabular}

Table 5. KMO and Bartlett's Test for factor of Mobile Phones.

\begin{tabular}{lll}
\hline Kaiser-Meyer-Olkin Measure of Sampling Adequacy. & $\mathbf{. 6 0 5}$ \\
\hline \multirow{3}{*}{ Bartlett's Test of Sphericity } & Approx. Chi-Square & 63.225 \\
& Df & 21 \\
& Sig. & .000 \\
\hline
\end{tabular}

\subsection{Factor Analysis}

In table 5, when Kaiser-Meyer-Olkin (KMO) measure of sampling adequacy of 0.605 and Bartlett's test of Sphericity approximate Chi-Square value of 63.225 are statistically significant at $5 \%$ level in Table 5 .

Also, using the criterion of retaining only factors with Eigen values of 1 or greater, the first three factors out of the six factors were retained for Principal Component analysis as given in table 6 . These three factors accounted for $22.468 \%$, $15.722 \%$ and $14.906 \%$ respectively of the total variance. $53.096 \%$ of the total variance was attributable to these three factors. The remaining four factors together accounted for $46.904 \%$ of the total variance in table 6 .

Table 6. Total Variance Explained.

\begin{tabular}{|c|c|c|c|c|c|c|c|c|c|}
\hline \multirow{2}{*}{ Component } & \multicolumn{3}{|c|}{ Initial Eigenvalues } & \multicolumn{3}{|c|}{ Extraction Sums of Squared Loadings } & \multicolumn{3}{|c|}{ Rotation Sums of Squared Loadings } \\
\hline & Total & $\%$ of Variance & Cumulative \% & Total & $\%$ of Variance & Cumulative \% & Total & $\%$ of Variance & Cumulative \% \\
\hline 1 & 1.421 & 23.684 & 23.684 & 1.421 & 23.684 & 23.684 & 1.385 & 23.083 & 23.083 \\
\hline 2 & 1.099 & 18.313 & 41.997 & 1.099 & 18.313 & 41.997 & 1.113 & 18.552 & 41.634 \\
\hline 3 & 1.015 & 16.923 & 58.920 & 1.015 & 16.923 & 58.920 & 1.037 & 17.286 & 58.920 \\
\hline 4 & .910 & 15.169 & 74.089 & & & & & & \\
\hline 5 & .833 & 13.875 & 87.964 & & & & & & \\
\hline 6 & .722 & 12.036 & 100.000 & & & & & & \\
\hline
\end{tabular}

Extraction Method: Principal Component.

Six factors were extracted on the basis of prior knowledge to describe the relationships among variables in a best way in table 6 . Further, the scree plot associated with this analysis is given in figure 3 . From the cumulative percentage of variance accounted for $58.920 \%$ of the variance. The contribution by first component and the second component were $23.083 \%$ and $41.634 \%$ of the total variance with a distinct break at percent at three factors as shown in figure 3.

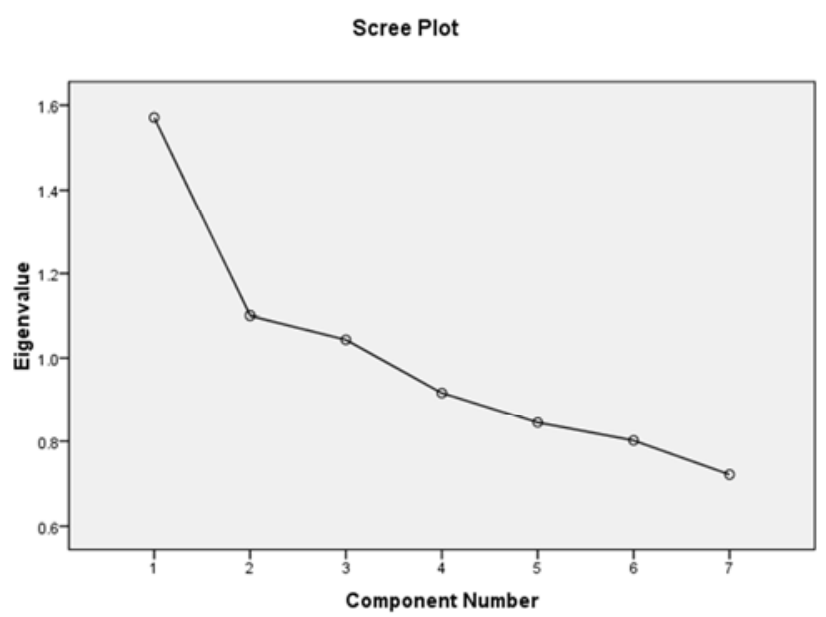

Figure 3. Scree Plot of Eigen value against Number of components.

\subsection{The Component Matrix and Interpretation of Extracted Factors}

The Component Matrix below represents the unrotated component analysis factor matrix, and presents the correlations that relate the six variables under study to the extracted factors. In table 7 below, the coefficients, called factor loadings, indicate how closely the variables are related to each factor. The correlation coefficients of 0.5 or greater are considered to be high and otherwise low.

Factor 1 contains four items (fashionable, level, more features and durability) that has coefficient more than 0.5 . The above rationalization had justified it to be user-friendly but indications of negative coefficient of three items (durability, portability, and price) shows that it has got no bearing on the user-friendly of the phone. That is, to say no matter how the price, portability and durability nature of the phone it is still considered as user-friendly. Factor 2 also contains two items (age and durability) that has coefficient more than 0.5 . This rationale also justified for quality as aged students will buy durable mobile phone not duet o mere fashion, portability or more features. The variable in factor three has a higher factor loading of 0.894 which depict customers' choice of brand of phone highly depended on price while portability and fashionable show a negative bearing on the price indicating that it is expensive. 
Table 7. Component Matrix ${ }^{a}$

\begin{tabular}{llll}
\hline \multicolumn{4}{l}{ Component } \\
\hline & 1 & 2 & 3 \\
Fashionable & .633 & .242 & -.100 \\
Level & .579 & .083 & .304 \\
More features & .567 & .092 & .001 \\
Durability & -.516 & .513 & .231 \\
Portability & -.487 & .013 & -.219 \\
Age & .028 & .871 & .201 \\
Price & -.107 & .064 & .894 \\
\hline
\end{tabular}

Extraction Method: Principal Component Analysis.

\section{Discussion}

This study was conducted to investigate the underlying reasons determining the choice of purchase of a brand of mobile phone(s). The three major factors directly influencing students' choice of brand of mobile phones in this study were userfriendliness, quality and price. Empirical literature on factors affecting mobile phone purchase worldwide has confirmed this finding [4]. Among all the mobile phone brands, the most used brand by the students in the study area was Nokia (31\%) and Samsung (25\%).Nokia and Samsung together constituted 56 percent of phones used by the students interviewed. While 31 percent of the respondents are using Nokia brand, 25 percent are using Samsung. This is an indication of students' preference for Nokia brand of phones [5].

Among the respondents, 45 percent preferred Nokia while 61 percent preferred Samsung. This means that most respondents are planning to shift to Samsung in the future irrespective of what they are using right now. This means Samsung is likely to be the leading patronized brand in the future with $61 \%$ consumers as compared to Nokia $45 \%$. Demand for Nokia has been impressive in the Ghanaian market for some time and seems demand is declining with preference for Samsung brand. The implication is that users of Nokia and Samsung phones may continue to use them if producers and marketers of these phone brands produce and market products that have attributes that meet the taste of their consumers.

The selling price of the brand of the mobile was one of the factors that influenced the decision of students to acquire a brand of a mobile phone in this study area. According to Sata, the price of a product is an important factor that cannot be overlooked in a study of consumer behavior [6]. Most of the respondents indicated price as the main consideration when deciding to buy a mobile phone. For the range of price which varied between $\mathrm{GHC} 50.00$ and $\mathrm{GHC}$ 301.00, the majority $(23 \%)$ purchased a brand of mobile phone which the price ranged between GHC151 and GHC 200. This indicates that price as an important factor influencing the decision and behavior of consumers in deciding to purchase a brand of a mobile phone. This finding is consistent with similar studies elsewhere [7], [8]. The mobile phone feature was also an important factor that influenced the students' decision to buy a brand of mobile phone. This is consistent with other studies [9], [10]. Fashion and durability were factors that correlated and have relationship with the decision to buy brand of mobile phone(s) with Pearson correlation coefficient of 0.877 and 0.083 . Both factors are highly associated with the quality of a given product [11], [12].

\section{Limitations and future studies}

With high mobile phone penetration and active mobile phone users in Ghana, the results of our study no doubt might guide other researches yet to be conducted in Ghana and other countries. However, we should bear in mind that the small sample size was due to our inability to study the whole population of University for Development Studies due to limited resources hence our in ability to generalize our results. The need for future research using both qualitative and quantitative studies is needed to provide in-depth and better understanding of students Knowledge, attitude and practices to get a broader and deeper understanding of the phenomenon.

\section{Conclusions}

This study has thrown some light on the preferred brand of mobile phones of a cross section of students in Ghana. Despite the above limitations and future studies needed, our findings suggest that consumers will be more sensitive to fashion and features. The findings thus contribute to the existing literature on consumer behavior in the mobile phone industry. For mobile phone operators, the findings of this study provide an important aspect of students' (consumer) choice of mobile phone brand such as features and fashion than any other consideration. As manufacturers of different mobile brands are working to improve on the quality of the brand, need to take into consideration the modern technological features. These preferences no doubt might eventually guide or influence manufacturers and marketers in the mobile phones industry to be aware of what to produce and sell. Equally, important is that it will also give mobile phone importers in Ghana a fair idea of the kind of mobile phones to import.

\section{References}

[1] Chisenga J. Entua-Mensah C. and Sam J. "Impact of Globalization on the Information needs of Farmers in Ghana: A. Case Study of Small-Scale Poultry Farmers". World Library and Information Congress Conference and Council,. Durban, South Africa 2007.

[2] Nyarko E. and Quartey L. "Liberalizing Ghana's Telecoms Sector: the Positives and the Negatives". PANOS West Africa Institute's LICOM Project, 2009.

[3] Frimpong GK. "Ghana Telecommunications Sector Performance Review: A. supply side analysis of Policy Outcomes". Science and Technology Policy Research Institute, Ghana, 2007.

[4] Dziwornu RK. "Factors Affecting Mobile Phone Purchase in the Greater Accra Region of Ghana: A. Binary Logit Model Approach".International Journal of Marketing Studies, Vol. 5, No. 6; 2013. 
[5] Aidoo E. \& Nyamedor BA"Study on Factors that determine the Choice of Brands of Mobile Phone: A. Case study in the Kumasi Metropolis". A. Bsc. Dissertation submitted to the Department of Mathematics and Statistics, University of Cape Coast, April, 2008.

[6] Sata M. "Factors Affecting Consumer Buying Behavior of Mobile Phone Devices". Mediterranean Journal of Social Sciences, Vol 4 No 12, 2013.

[7] Karjaluoto H, Karvonen J, Pakola J, Pietilä M, Salo J and Svento R. "Exploring consumer motives in mobile phone industry: An investigation of Finnish mobile phone users". Proceedings of the 1st International Conference on Business Economics, Management, and Marketing (Athens, Greece), $2003 ; 3,335-342$.

[8] Saif N, Razzaq N, Amad M, Gul S. "Factors Affecting Consumers' Choice of Mobile Phone Selection in Pakistan". European Journal of Business and Management, 4(12), 2012, PP. 16-26.
[9] Pakola J, Pietilä M Svento R, Karjaluoto H. "An investigation of Consumer Behaviour in Mobile Phone Markets in Finland". Submission to 32rd EMAC Conference, Track: New Technologies and E-Marketing, 2007.

[10] Malasi JM. "Influence of Product Attributes on Mobile Phone Preference among University Students: A. Case of Undergraduate Students". International Journal of Academic Research and Management Sciences, 1(6), 2012, PP.22263624 .

[11] Zhou N, and ShanturkovskaG. "Chinese Consumer Behavior in the Mobile Phone Market: Nokia Case" (Doctoral dissertation, Gotland University, 2011.

[12] Das D. "An Empirical Study of Factors Influencing Buying Behavior of Youth Consumers towards Mobile Hand Sets: A. Case Study In Coastal District of Odisha", Asian Journal of Research in Business Economics and Management,Vol. 2, No. 4, 2012, pp. 68-82. 